\title{
Comparative Investigation of River Water Quality by OWQI, NSFWQI and Wilcox Indexes (Case study: the Talar River - IRAN)
}

\author{
Gholamreza Darvishi ${ }^{1}$, Farshad Golbabaei Kootenaei²*, Maedeh Ramezani ${ }^{3}$, Eissa Lotfi ${ }^{4}$, \\ Hosseinali Asgharnia ${ }^{5}$ \\ ${ }^{1}$ Babol Noshirvani University of Technology, Iran \\ Faculty of Civil \& Environmental Engineering \\ ${ }^{2}$ University of Tehran, Iran \\ Graduate Faculty of Environment, Department of Environmental Engineering \\ ${ }^{3}$ Islamic Azad University, Iran \\ Young Researchers and Elite Club \\ ${ }^{4}$ Regional Water Company of Mazandaran, Iran \\ ${ }^{5}$ Babol University of Medical Sciences, Iran \\ Department of Environmental Health \\ *Corresponding author's e-mail: farshadgolbabaei@yahoo.com
}

Keywords: Talar River, Water Quality, OWQI, NSFWQI, Wilcox.

\begin{abstract}
Rivers are considered as one of the main resources of water supply for various applications such as agricultural, drinking and industrial purposes. Also, these resources are used as a place for discharge of sewages, industrial wastewater and agricultural drainage. Regarding the fact that each river has a certain capacity for acceptance of pollutants, nowadays qualitative and environmental investigations of these resources are proposed. In this study, qualitative investigation of the Talar river was done according to Oregon Water Quality Index (OWQI), National Sanitation Foundation Water Quality Index (NSFWQI) and Wilcox indicators during 2011-2012 years at upstream, midstream and downstream of the river in two periods of wet and dry seasons. According to the results of OWQI, all of the values at 3 stations and both periods are placed at very bad quality category and the water is not acceptable for drinking purposes. According to NSFWQI, the best condition was related to the upstream station at wet season period (58, medium quality) and the worst condition was related to the downstream in wet season period (46, very bad quality). Also the results of Wilcox showed that in both periods of wet season and dry season, the water quality is getting better from upstream station to the downstream station, and according to the index classification, the downstream water quality has shown good quality and it is suitable for agriculture.
\end{abstract}

\section{Introduction}

For proper application of water resources, communities, agricultural and industrial centers are usually constructed next to the rivers (Srinivas et al. 2013, Shamsai et al. 2006). Because of the increase of population, industrial development, increase of water salinity, pouring various organic and mineral pollutants into rivers as sewage and etc. Rivers are water bodies most vulnerable to pollution due to their role in transporting point and non-point discharges in their vast drainage basins (Boyacioglu 2014) and rivers are being contaminated and this contamination of water resources in most of the rivers around the world leads to serious threats to environment, agricultural products and human health (Jafarabadi 2012, Godghate et al. 2013). In many countries such as Iran, social and industrial developments changed the qualitative characteristics of the river water and leads to excessive pollution. Therefore, overall national planning and resource management in respect to water with emphasis on allocation of priorities among the different uses is necessary. It is not surprising that, due to the above factors, studying water quality is so much important to be carried out in order to keep our awareness and understanding of our environment (Abdul Hameed et al. 2010). Regarding apparent difference between limitation of water resources and daily increasing demand for these resources at communities, the emphasis is placed on continuous monitoring, control and treatment of surface waters. Therefore, continuous measurement and analysis of qualitative parameters of rivers are considered as the main issue for identification of water quality. While until now, limited studies of a few rivers have been done in Iran, nowadays in many developed countries, qualitative zoning of rivers have became a basic method for proper management of 
water resources (Cheraghi et al. 2007, Rahimi 2003). As a result, qualitative studies and zoning of rivers according to indicators of water quality standard, not only clear the qualitative conditions of the river water, it also leads to sustainable development and help to increase the productivity of the river (Mirmoshtaghi 2012, Bharti et al. 2011). By identifying those sections of the river where the water quality parameters are lower than the standard values, finding proper solutions for removing of these pollutants will become easier (Nazari et al. 2005, Eneji et al. 2012). Among the various indexes which are applicable for water quality zoning, NSFWQI was selected because of high precision, simplicity and availability of the required parameters (Shamsai et al. 2006, Zandbergen et al. 1988), and also OWQI index was selected and used because of being strict and having no weighting parameters which are involved in the index.

In 2011, Mirmoshtaghi studied the water quality of the Sefidrood River by investigating 20 samples at 5 sampling stations according to NSFWQI index and compared the results with OWQI index. The results showed that maximum and minimum values of NSF were 57 and 32, respectively. And the average value of NSFWQI for Sefidrood River equals to 47.5, which classifies it as a bad region. Also, calculation of OWQI index showed the very bad quality of the Sefidrood River water during the study period (Mirmoshtaghi 2012). Shamsai in 2006 studied 3 quality indicators of OWQI, NSFWQI and BCWQI for qualitative zoning of the Karoon River and the Dez River during 3 years. The results obtained from comparing these indexes showed that NSFWQI is preferred because of direct involvement of measured parameters on structure of sub-index and total-index and also by considering the weight effect on sensitivity (Shamsai et al. 2006). A similar study was conducted by Curtis in 2001. He studied the OWQI calculation method and type of sampling from the Oregon River, by investigating parameters such as $\mathrm{pH}$, total solids, fecal coliform, phosphate, dissolved oxygen, $\mathrm{BOD}_{5}$, nitrate and temperature. The results of that study showed that the OWQI index is a good indicator for zoning of the river. In another study, Cude showed the usefulness of the Oregon water quality index as a tool for water quality management. The Oregon water quality index is a single value which is representative of the water quality and obtained by combining the values of the eight above mentioned water quality variables (Cude 2001).

In this study, the water quality index (WQI) was represented by three indexes of NSFWQI, OWQI and Wilcox to evaluate the spatial and temporal changes of surface water quality in the Talar River, the scores calculated were used for classifying the water quality and assessing the impacts of industrial and rapid urbanization on the overall water quality of the river.

\section{Material and Methods}

To determine the structure of surface waters quality indexes, the data prepared by measurement of water quality parameters are considered as base of the progress. Although, depending upon the kind of the index and its objectives, the parameters are different. These parameters are representative of the chemical, physical and biological characteristics of the water. The functions and relations that build the mathematical structure of the indexes affect these parameters and finally present the index as a single number (Liu et al. 2012).

\section{National Sanitation Foundation Water Quality Index (NSFWQI)}

NSFWQI is one of the most widely used indicators which comprises nine main parameters such as $\mathrm{pH}$, total solids, fecal coliform, total phosphate, dissolved oxygen, $\mathrm{BOD}_{5}$, nitrate, turbidity and temperature. NSFWQI is obtained as below:

$$
\mathrm{NSFWQI}=\sum \mathrm{W}_{\mathrm{i}} \mathrm{I}_{\mathrm{i}}
$$

In this equation, $\mathrm{I} i$ is the quality of the ith parameter (a number between 0 and 100 read from the appropriate subindex graph) and Wi is the weight factor of the ith parameter (Badalians Gholikandi et al. 2012).

After measuring the above characteristics, the sub-index of each of them is obtained from conversion curves. These curves convert the parameters into measures that range from zero to 100. To calculate the final index in this method, each sub-index obtained from the related curves is multiplied by weight factor, and the final index is obtained by the sum of them, according to Equation 1 (Ebrahimpur et al. 2012). For the calculation of NSFWQI and determination of Qi, the Wilcox Standard Graphs are used (Shamsai et al. 2006, Fabiano et al. 2008, Sanchez 2007). Classification of river pollution intensity and water description according to NSFWQI are presented in Table 1.

\section{Oregon Water Quality Index (OWQI)}

Generally, this index is used to assess water quality for recreational purposes. Simplicity, availability of required quality parameters, and the determination of sub-indexes by curve or analytical relations are some advantages of this approach. In this method, each of the eight parameters (as mentioned before) is no-weighting factor and has same effect on the final factor. Table 2 presents a water description according to the index numerical values. The final Oregon index is calculated by Equation 2; in this formula, $\mathrm{n}$ is the number of parameters

Table 1. Classification of river pollution intensity according to NSFWQI index

\begin{tabular}{|c|c|c|}
\hline Calculated index & Class & Water Quality Condition \\
\hline $91-100$ & A & Excellent \\
\hline $71-90$ & B & Good \\
\hline $51-70$ & C & Bedium \\
\hline $26-50$ & D & Very Bad \\
\hline $0-25$ & E & \\
\hline
\end{tabular}


$(n=8)$ and $\mathrm{SI}_{i}$ is the value of parameter $\mathrm{i}$ (Ebrahimpur et al. 2012). This index is calculated by Equation 2:

$$
O W Q I=\frac{n}{\sqrt{\sum_{i=1}^{n} \frac{1}{S I^{2}{ }_{i}}}}
$$

The standard graphs are used to calculate the SI (Shamsai et al. 2006). Finally, the pollution and water quality of the river is assessed according to Table 3 .

\section{Wilcox indicator}

Nowadays, this index is considered as a very common method for classifications of water for agricultural purposes. In this classification, two factors, Electrical Conductivity (EC) and Sodium Adsorption Ratio (SAR) are considered and each of them is divided into four sections which finally lead to the creation of totally 16 groups. The groups are classified as follows:
(1) Very good water with EC less than $250 \mu \mathrm{mohs} / \mathrm{cm}$, it is in class $\mathrm{C}_{1} \mathrm{~S}_{1}$.

(2) Good water that is related to one of $\mathrm{C}_{2} \mathrm{~S}_{1}$ or $\mathrm{C}_{2} \mathrm{~S}_{2}$ groups.

(3) Medium water that is related to one of $\mathrm{C}_{3} \mathrm{~S}_{3}, \mathrm{C}_{3} \mathrm{~S}_{2}, \mathrm{C}_{3} \mathrm{~S}_{1}$, $\mathrm{C}_{2} \mathrm{~S}_{3}, \mathrm{C}_{1} \mathrm{~S}_{3}$ groups and is suitable for irrigation of lands with good drainage.

(4) Unsuitable water for irrigation that is related to one of $\mathrm{C}_{4} \mathrm{~S}_{3}$, $\mathrm{C}_{4} \mathrm{~S}_{2}, \mathrm{C}_{1} \mathrm{~S}_{4}, \mathrm{C}_{2} \mathrm{~S}_{4}, \mathrm{C}_{3} \mathrm{~S}_{4}, \mathrm{C}_{4} \mathrm{~S}_{4}, \mathrm{C}_{4} \mathrm{~S}_{4}$ groups (Saghi 2011), and as the index is greater the quality is lower (Rahmani 2008). Tables 3 and 4 show classification of water for agricultural purposes.

\section{Locations of sampling stations}

Location Map of the Talar River in Mazandaran province is shown in Fig. 1. For the determination of sampling stations along the river pathway, some issues including the discharge place of municipal and industrial wastewater, agricultural drainage and other sources of pollutants into the river, the qualitative effects of branches of river water and availability of

Table 2. Average values of river water index according to OWQI index

\begin{tabular}{|c|c|c|}
\hline Numerical value & Condition & Color \\
\hline $90-100$ & Excellent & Blue \\
\hline $85-89$ & Good & Green \\
\hline $70-84$ & Medium & Yellow \\
\hline $60-70$ & Bad & Orange \\
\hline $10-59$ & Very Bad & Red \\
\hline
\end{tabular}

Table 3. Agricultural water classification according to SAR

\begin{tabular}{|c|c|c|}
\hline SAR & Classification & Quality of Alkaline \\
\hline$<10$ & $\mathrm{~S}_{1}$ & Low \\
\hline $10-18$ & $\mathrm{~S}_{2}$ & Medium \\
\hline $18-26$ & $\mathrm{~S}_{3}$ & High \\
\hline$>26$ & $\mathrm{~S}_{4}$ & Very high \\
\hline
\end{tabular}

Table 4. Agricultural water classification according to EC

\begin{tabular}{|c|c|c|}
\hline EC ( $\boldsymbol{\mu m o h s / c m )}$ & Classification & Quality of the soil \\
\hline $100-250$ & $\mathrm{C}_{1}$ & Low \\
\hline $250-750$ & $\mathrm{C}_{2}$ & Medium \\
\hline $750-2250$ & $\mathrm{C}_{3}$ & High \\
\hline$>2250$ & $\mathrm{C}_{4}$ & Very high \\
\hline
\end{tabular}

Table 5. Locations of the stations

\begin{tabular}{|c|c|c|c|}
\hline \multirow{2}{*}{ Station } & \multicolumn{2}{|c|}{ Locations of Stations } \\
\cline { 2 - 4 } & Latitude & Longitude & $\begin{array}{c}\text { The Average Height } \\
\text { of the Basin }(\mathrm{m})\end{array}$ \\
\hline Pole-Sefid (Upstream) & 3998373 & 685267 & 637 \\
\hline Shirgah (Middle stream) & 401878 & 669383 & 253 \\
\hline Kiakola (Downstream) & 4047543 & 662205 & 6 \\
\hline
\end{tabular}


the stations were considered (Fataei et al. 2013). Locations of the stations are presented in Table 5.

\section{Under Study Parameters}

The variables studied in this research consist of nitrate, phosphate, total solids, $\mathrm{pH}$, temperature, turbidity, fecal coliform, DO (Dissolved Oxygen) and $\mathrm{BOD}_{5}$. All of these parameters are measured according to the standard methods (APHA, 2005).

\section{Results and discussion}

Table 6 presents the average values of parameters during two periods of wet season and dry season at three zones of upstream, midstream and downstream, during six sampling months at three stations according to available standards.
The values of NSFWQI during two periods of dry and wet season are shown in Fig. 2.

According to NSFWQI, none of the stations at all sampling months had a good or excellent water quality and at best conditions. Station No.1 which is less polluted and does not have any wastewater discharge during the two periods, has just a moderate quality. The reasons for this are natural low value of $\mathrm{pH}$ in the Talar River, irrigation of upstream agricultural lands and entry of chemical fertilizers, pesticides and manure into the stream (Banjaka et al. 2012). The values of OWQI during two periods of dry and wet season are shown in Fig. 3.

The OWQI value at all of the stations in all sampling months was between 15 and 20 that is an indicator of "very bad" water quality hencethe Talar river water is not suitable for fishing and recreational purposes (Boskidisa et al. 2011).

Table 6. Average results of parameters during periods of wet season and dry season

\begin{tabular}{|c|c|c|c|c|c|c|}
\hline \multirow{2}{*}{ Parameter } & \multicolumn{3}{|c|}{ Wet season } & \multicolumn{3}{|c|}{ Dry season } \\
\hline & Upstream & Middle stream & Downstream & Upstream & Middle stream & Downstream \\
\hline $\mathrm{DO}(\mathrm{mg} / \mathrm{L})$ & 7.31 & 8.05 & 4.183 & 8.96 & 9.16 & 5.45 \\
\hline $\mathrm{BOD}_{5}(\mathrm{mg} / \mathrm{L})$ & 0.5 & 0.78 & 0.583 & 0.65 & 1.31 & 6.11 \\
\hline $\mathrm{TS}$ (mg/L) & 3211 & 2889.5 & 2664.16 & 1794.41 & 747.16 & 1382.83 \\
\hline Turbidity (NTU) & 1022.11 & 2398.66 & 2260.83 & 338.5 & 715.83 & 536.76 \\
\hline Temperature $\left({ }^{\circ} \mathrm{C}\right)$ & -1.41 & 2.33 & 4 & 9.83 & 16 & 17.83 \\
\hline $\mathrm{pH}$ & 8.13 & 8.15 & 8.13 & 8.16 & 8.05 & 8.08 \\
\hline $\begin{array}{l}\text { Fecal coliform } \\
\text { (Colony/100ml) }\end{array}$ & 1047.16 & 2366.66 & 2160 & 1585 & 3016.66 & 2466.66 \\
\hline Nitrate (mg/L) & 5.11 & 5.075 & 4.0 & 3.73 & 9.63 & 7.51 \\
\hline Phosphate (mg/L) & 0.113 & 0.253 & 0.236 & 0.173 & 0.181 & 0.205 \\
\hline
\end{tabular}

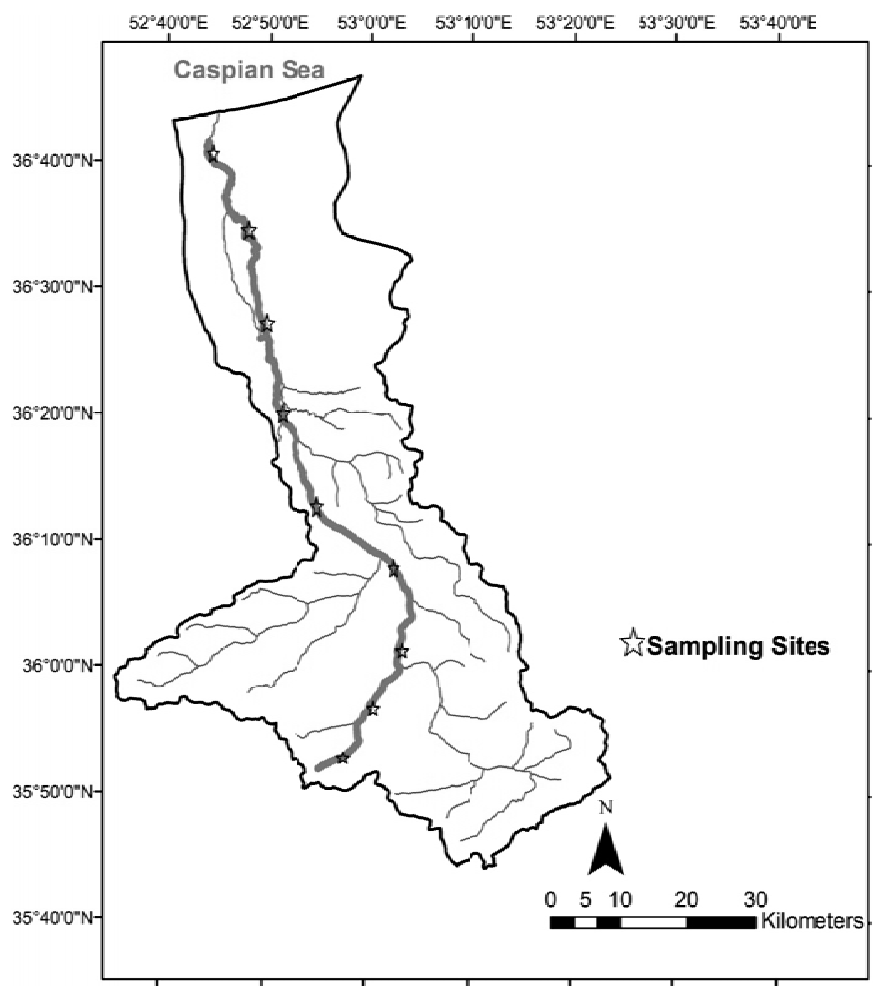

Fig. 1. Location Map of the Talari River in Mazandaran province 


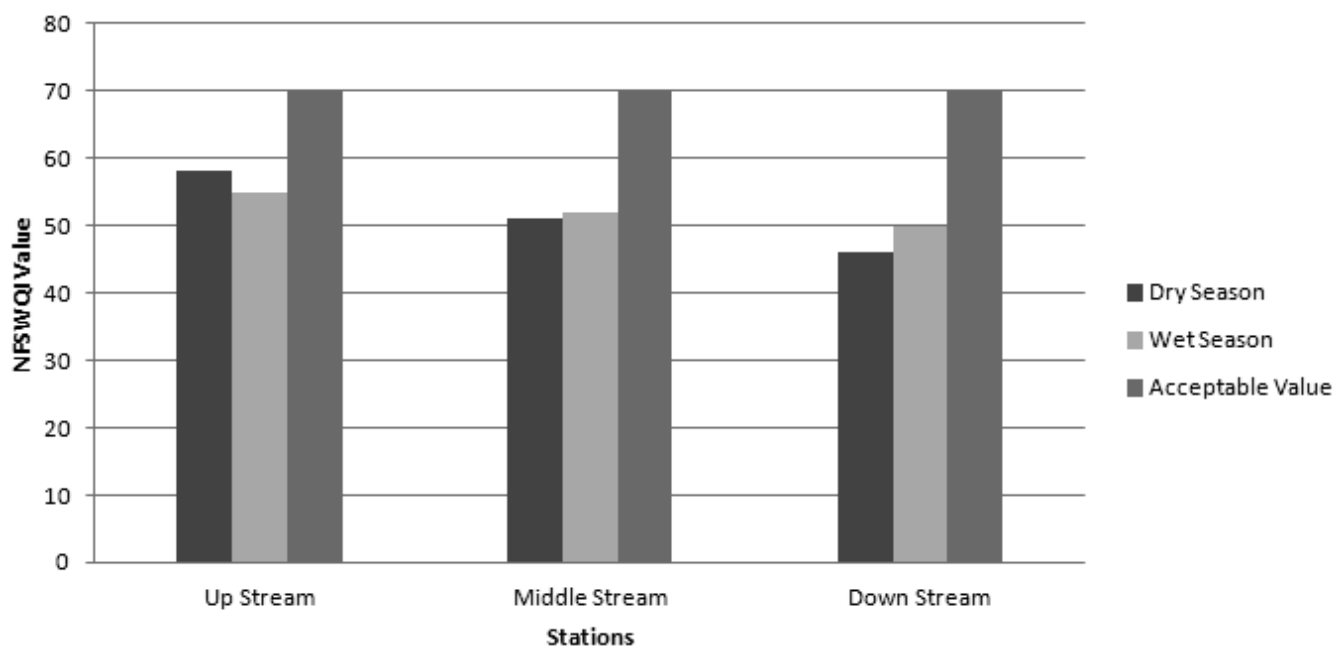

Fig. 2. NSFWQI changes trend in the Talar river

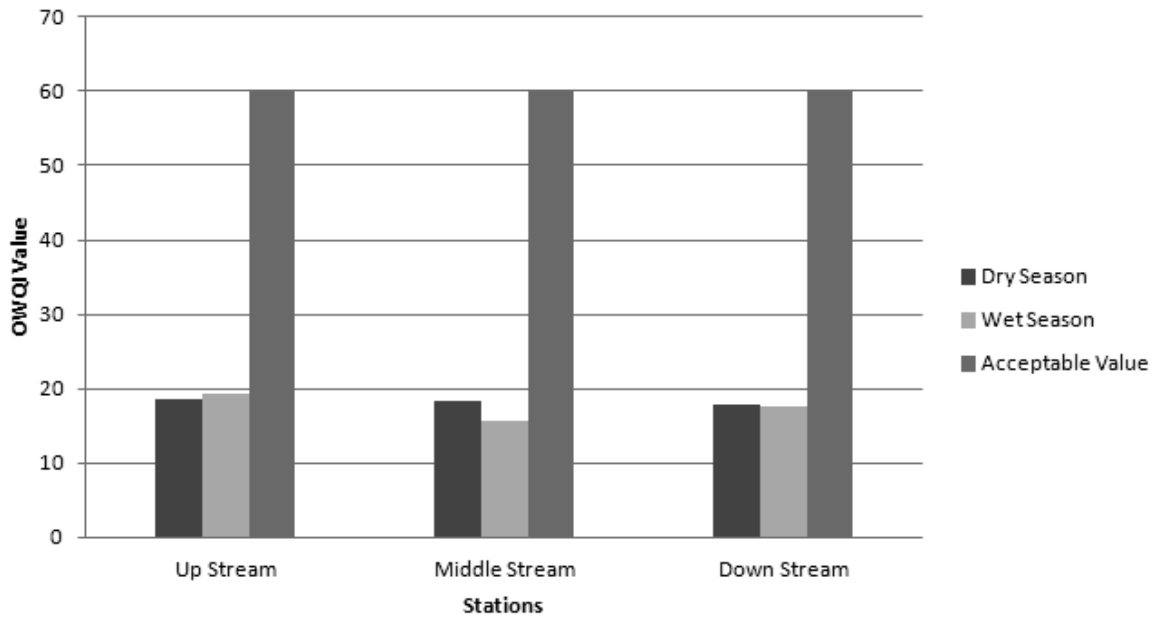

Fig. 3. OWQI changes trend in the Talar River

\section{Comparison of OWQI and NSFWQI changes trend in various periods}

OWQI and NSFWQI changes trend in wet and dry seasons at various stations are shown in Figs 4 and 5.

The comparison of OWQI and NSFWQI showed that NSFWQI is more suitable for the Talar river zoning, because it well shows the entering of pollution into the river along its pathway during sampling months. Also because of weighting parameters that are involved with NSFWQI, this index is distinct from OWQI. The study of Hooshmand in 2009 confirms this result that NSFWQI has a higher efficiency in comparison with OWQI (Hooshmand et al. 2009). Also, Fabiano in 2008 investigated the NSFWQI on the Macaco and the Kiocsada Rivers and the results of this study showed that NSFWQI is an acceptable indicator for zoning of the both studied rivers (Fabiano et al. 2008). Also, the study of Simeonov et al. in 2003 conducted on surface water quality of Northern Greece showed that by least treatment the water in this condition can be potable (Simeonov et al. 2003).

\section{Wilcox numerical value}

The amount of Wilcox indicator at study stations is presented in Table 7.
According to Wilcox, in each period, the water pollution is decreased from upstream to downstream and conversely, water quality is increased because of EC and SAR reduction. Also, the water samples from the river in all sampling months and stations showed that the Talar river water is in $\mathrm{S}_{1}$ condition (low alkalinity) and $\mathrm{C}_{2}-\mathrm{C}_{3}$ classes, according to SAR and $\mathrm{EC}$, respectively. Generally, based on Wilcox the Talar river water is pretty suitable for agriculture in all sampling months and stations (Kowalkowski et al. 2007).

\section{Conclusions}

Population load and excess urban activity in the basin of this river, industrial activities, excessive consumption of chemical fertilizers and pesticides, discharge of rural, urban and industrial wastewater and also solid wastes into the river which have a continuous increasing trend are the main source of river pollution. So, human factor is the main cause of river pollution. Besides human factors, natural factors such as low rainfall, water consumption for agricultural and industrial purposes, development of agricultural lands at the expense of natural lands wastefulness and finally, increased physical and chemical pollution of the river that leads to 


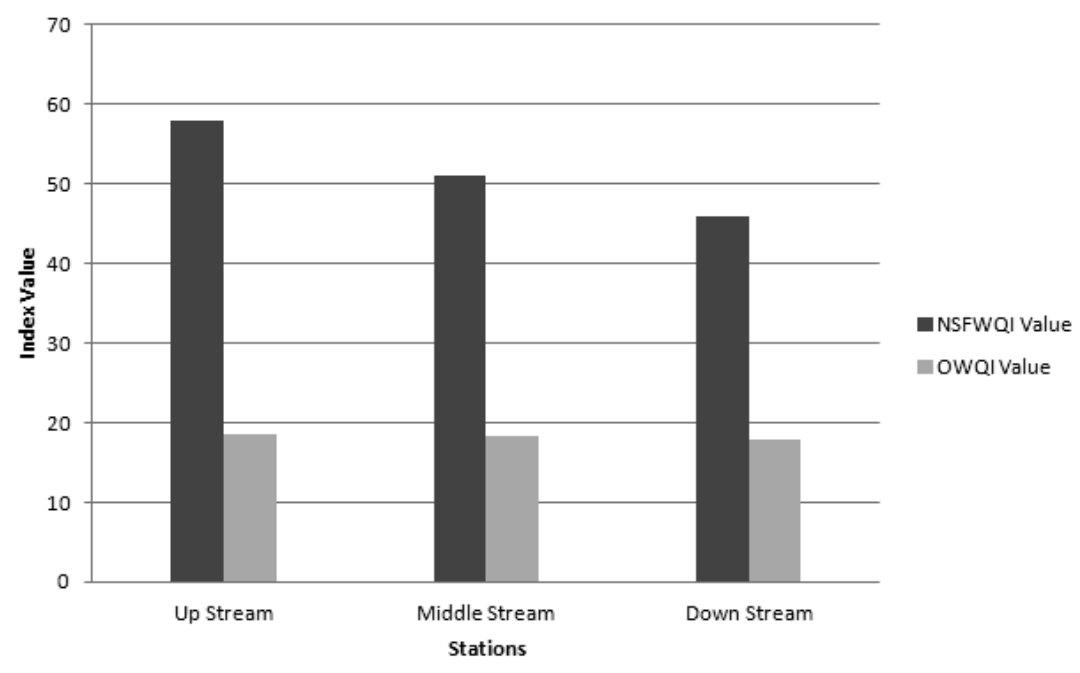

Fig. 4. Comparison of OWQI and NSFWQI changes trend in wet season

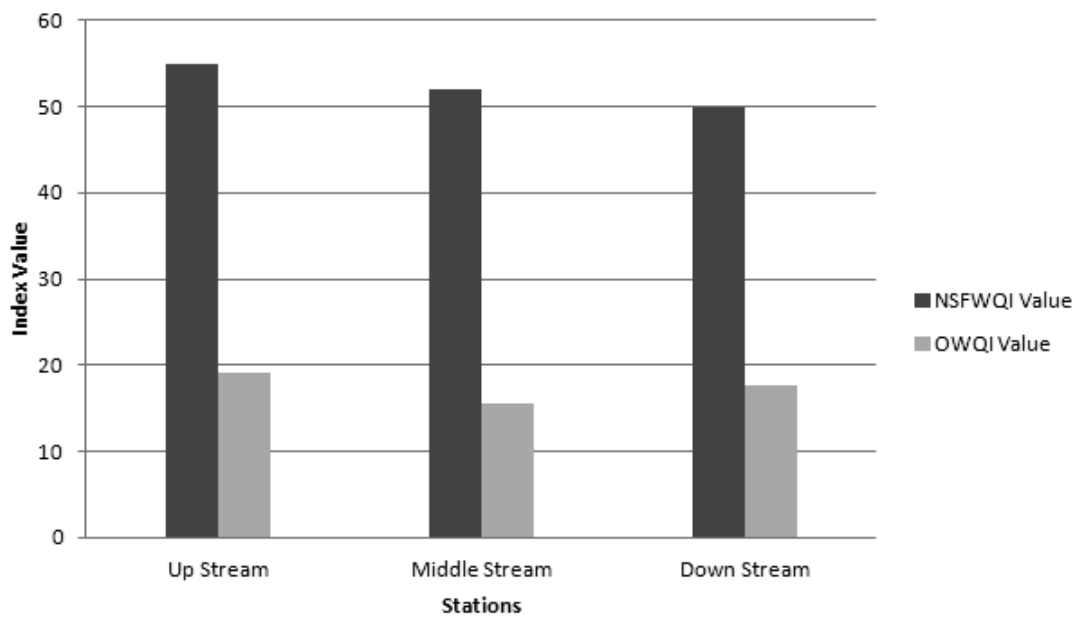

Fig. 5. Comparison of OWQI and NSFWQI changes trend in dry season

Table 7. NSFWQI water quality index in two periods of wet and dry season

\begin{tabular}{|c|c|c|c|c|}
\hline \multirow{2}{*}{ Stations } & \multicolumn{2}{|c|}{ Wet season } & \multicolumn{2}{|c|}{ Dry season } \\
\cline { 2 - 5 } & Qualitative Condition & Index Value & Qualitative Condition & Index Value \\
\hline Up stream & Average & 58 & Average & 55 \\
\hline Middle stream & Average & 51 & Average & 52 \\
\hline Down stream & Bad & 46 & Bad & 50 \\
\hline
\end{tabular}

natural disruption of its biological and bioavailability capacity.

In this study, the river water quality is different for OWQI index and NSFWQI index. The reason for this can be due to the fact that OWQI is stricter than NSFWQI. According to OWQI, the DO, $\mathrm{BOD}_{5}$ and turbidity at station No.1 are at acceptable values of standards and there is no wastewater discharge into it, but, because of high nitrate and phosphate contents (due to the use of chemical fertilizers and pesticides at upstream), low $\mathrm{pH}$ and interactions between these parameters, station No.1 does not have a good quality water (Saha 2010). In terms of drinking purposes, water quality at station No.1 was better than in other stations and by least treatment and $\mathrm{pH}$ adjustments it can be potable. But water at other stations needs more advanced treatment to become acceptable for drinking purposes (Wongsupapa 2009).

According to the studies which present the current conditions of the Talar River, three conclusions can be considered:

Generally, it comes from the interpretations of the results based on NSFWQI that along the Talar river pathway from upstream station to the outlet of the Caspian Sea, the pollution load is increased and water quality is decreased. The NSFWQI value at upstream station was more than 50 and at down-stream station (in both periods) was less than 50, which is indicator of bad conditions. So, according to NSFWQI, the average quality of the Talar river water is moderate. 
Table 8. OWQI index in two periods of wet and dry season

\begin{tabular}{|c|c|c|c|c|}
\hline \multirow{2}{*}{ Stations } & \multicolumn{2}{|c|}{ Wet season } & \multicolumn{2}{c|}{ Dry season } \\
\cline { 2 - 5 } & Qualitative Condition & Index Value & Qualitative Condition & Index Value \\
\hline Up stream & Very bad & 18.62 & Very bad & 19.22 \\
\hline Middle stream & Very bad & 18.42 & Very bad & 15.58 \\
\hline Down stream & Very bad & 17.89 & Very bad & 17.68 \\
\hline
\end{tabular}

Table 9. Wilcox value at study stations in wet and dry seasons

\begin{tabular}{|c|c|c|c|c|}
\hline \multirow{2}{*}{ Station } & \multicolumn{2}{|c|}{ Wet season } & \multicolumn{2}{c|}{ Dry season } \\
\cline { 2 - 5 } & Qualitative Index & Qualitative Condition & Qualitative Index & Qualitative Condition \\
\hline Upstream & $\mathrm{C}_{3} \mathrm{~S}_{1}$ & Medium & $\mathrm{C}_{3} \mathrm{~S}_{1}$ & Medium \\
\hline Middle stream & $\mathrm{C}_{2} \mathrm{~S}_{1}$ & Good & $\mathrm{C}_{3} \mathrm{~S}_{1}$ & Medium \\
\hline Downstream & $\mathrm{C}_{2} \mathrm{~S}_{1}$ & Good & $\mathrm{C}_{2} \mathrm{~S}_{1}$ & Good \\
\hline
\end{tabular}

According to the results of the OWQI index experiments, the water quality of the river is in "very bad" condition so the Talar river water is not suitable for fishing and recreational purposes.

Based on Wilcox index, the Talar river water is suitable for agricultural purposes in entire river and on every day of the year.

\section{References}

Alobaidy, A.H.M.J., Abid, H.S. \& Maulood, B.K. (2010). Application of water quality index for assessment of Dokan Lake ecosystem, Kurdistan Region, Iraq, Journal of Water Resource and Protection, 2010, 2, pp. 792-798.

APHA (2005). Standard Methods for the Examination of Water and Wastewater. 21st ed, American Public Health Association/ /American Water Works Association/Water Environment Federation, Washington, DC, USA, 2005.

Godghate, A., Sawant, R. \& Jadhav, S. (2013). An evaluation of physico-chemical parameters to assess borewell water quality from Madyal and Vadgaon villages of Kagal Tahsil, MS, India, International Research Journal of Environment Sciences, 2(5), pp. 95-97.

Gholikandi, G.B., Haddadi, S., Dehghanifard, E. \& Tashayouie, H.E.(2012) Assessment of surface water resources quality in Tehran province, Iran, Desalination and Water Treatment, 37: $1-3$, pp. 8-20.

Banjaka, D. \& Nikolic, J. (2012). Hydrochemical characteristics and water quality of the Musnica River catchment, Bosnia and Herzegovina, Hydrological Sciences Journal, 57(3), 2012, pp. $562-575$.

Bharti, N \& Katyal, D. (2011) Water quality indices used for surface water vulnerability assessment, International Journal of Environmental Sciences, 2(1), pp. 154-173.

Boskidisa, I., Gikasa, G., Sylaiosa, G. \& Tsihrintzis, V. (2011). Water quantity and quality assessment of lower Nestos river, Greece, Journal of Environmental Science and Health, Part A: Toxic/Hazardous Substances and Environmental Engineering, 46(10), pp. 1050-1067.

Boyacioglu, H. (2014). Spatial differentiation of water quality between reservoirs under anthropogenic and natural factors based on statistical approach, Archives of Environmental Protection, 40 (10), pp. 41-50.
Cheraghi, M. \& Khorasani, N. (2007) Investigation of Godar-e-Khosh river sources of pollution, School of Natural Resources Journal, 3, pp. 659-668.

Cude, C.G. (2001). Oregon water quality index: a tool for evaluating water quality management effectiveness, American Water Resources Association Journal, 37(1), pp.125-137.

Ebrahim Pur, S., Mohammad Zadeh, H. \& Mohammadi, A. (2012) Qualitative investigation of Zarivar lake water and it's zoning according to OWQI and NSFWQI by GIS, paper presented at the 4th Iranian Water Resource Management Conference, University of Amirkabir, Tehran, Iran 2012.

Eneji, I., Onuche, A. \& R. Shaato, (2012). Spatial and temporal variation in water quality of River Benue, Nigeria, Journal of Environmental Protection, 3, pp. 915-921.

Fabiano, D., Santos, S., Altair, B., Sonia, M., Nobre, G. \& Maria, J. (2008). Water quality index as a simple indicator of aquaculture effects on aquatic bodies, Ecological Indicators, 8, pp. 476-484.

Fataei, E., Seyyedsharifi, A., Seiiedsafaviyan, T. \& Nasrollahzadeh, S. (2013). Water quality assessment based on WQI and CWQI Indexes in Balikhlou River, Iran, Journal of Basic Applied Sciences Research, 3(3), pp. 263-269.

Hooshmand, A., Delghandi, M. \& Kaboli, H. (2009). Water qualitative zoning of Karoon river according to WQI by GIS system, paper presented at the 2th National Conference and Exhibition of Environmental Engineering, Tehran University, Iran 2009.

Jafarabadi, A. (2012). Investigation on causes of pollution in Zayanderood river and its qualitative estimation by NSFWQI, paper presented at the 5th National Conference and Exhibition of Environmental Engineering, Tehran University, Iran 2012.

Kowalkowski, T., Cukrowska, E.M., Hlobsile Mkhatshwa, B. \& Buszewski, B. (2007). Statistical characterisation of water quality in Great Usuthu River (Swaziland), Journal of Environmental Science and Health, Part A: Toxic/Hazardous Substances and Environmental Engineering, 42(8), 2007, pp. 1065-1072.

Liu, Z., Sun, G., Huang, S., Sun, W., Guo, J. \& Xu, M. (2012). Water Quality Index as a simple indicator of drinking water source in the Dongjiang River, China, International Journal of Environmental Protection, 2 (5), pp. 16-21.

Mir-Moshtaghi, M. (2012). Qualitative investigation of sefid-rood river water and its zoning according to NSFWQI and OWQI, Journal of Wetlands, 15, 4, pp. 1-6.

Nazari, H., Ghodseyan, M. \& Khodadadi, A. (2005) Study of pollutant effect on Shafa-rood water quality in Gilan province, 
paper presented at the 5th National Conference in Environmental Engineering, Tehran, pp. 43-51, Iran 2005.

Rahimi, V. (2003) Investigation of distribution of pollutants in Sefid-rood river and the methods of managing them, dissertation, Faculty of Technical Science, Tarbiat-Modares University, Iran 2003.

Rahmani, A. (2008). Determination of water quality in current rivers of Dasht-e-Hamedan according to WILCOX indicator, paper presented at the 10th National Conference of Environmental Health, Tehran, pp. 8-10, Iran 2008.

Saghi, H. (2011) Qualitative zoning of Morad-Beik river in Hamedan (Iran) by NSFWQI, BCWQI, CWQI, OWQI and WILCOX, dissertation, University of Hamedan, Iran 2011.

Saha, P. (2010). Assessment of Water Quality of Damodar River by Water Quality Index Method, Indian Chemical Engineer, 52(2), pp. $145-154$

Sanchez, E. (2007). Use of the water Quality index and dissolved oxygen deficit as simple indicators of watershed pollution, Journal of Ecological Indicators, 7, pp. 315-328.
Shamsai, A., Urei, S. \& Sarang, A. (2006) Comparative of qualitative indexes and qualitative zoning of Karoon river and Dez river, Journal of Water and Wastewater, 16, pp. 88-97.

Simeonov, V., Stratis, J.A., Samara, C., Zachariadis, G., Voutsa, D., Anthemidis, A., Sofoniou, M. \& Kouimtzis, T. (2003). Assessment of the surface water quality in Northern Greece, Journal of Water Resources, 37, pp. 4119-4124.

Srinivas, J., Purushotham, A.V. \& Murali Krishna, K.V.S.G. (2013). Determination of water quality index in industrial areas of Kakinada, Andhra Pradesh, India, International Research Journal of Environment Sciences, 2(5), pp. 37-45.

Wongsupapa, C., Weesakula, S., Clementea, R. \& Das Gupta, A. (2009). River basin water quality assessment and management: case study of Tha Chin River Basin, Thailand, Water International, 34(3), pp. 345-361.

Zandbergen, P. \& Hall, K. (1988). Analysis of the British Columbia Water Quality Index for watershed manager: a case study of two small watersheds, Journal of Water Quality, 33, pp. 519-525. 